Dedicated to Professor Emeritus Ioan A. Rus on the occasion of his $80^{\text {th }}$ anniversary

\title{
Caristi's random fixed point theorem for generalized distance on Polish spaces
}

\section{Areerat Arunchai ${ }^{1}$ and Somyot Plubtieng ${ }^{1,2}$}

\begin{abstract}
.
In this paper, we present the random version of generalized Caristi's fixed point theorem for generalized distance on Polish spaces. Moreover, we prove some Caristi's random fixed point theorems for multi-valued mappings on Polish spaces. Our results in this paper extend and improve some known results in the literature.
\end{abstract}

Acknowledgements. The authors would like to thank Naresuan University and Thailand Research Fund (TRF) for supporting by permit money of investment under of The Royal Gloden Jubillee Ph.D. Program (RGJ-Ph.D.), Thailand.

\section{REFERENCES}

[1] Aubin, J. P. and Frankowska, H., Set-Valued Analysis, Birkhauser, Boston, 1990

[2] Bae, J. S., Fixed point theorems for weakly contractive multivalued maps, J. Math. Anal. Appl., 284 (2003), 690-697

[3] Banach, S., Sur les opérations dans les ensembles abstraits et leur application aux équations intégrales, Fund. Math., 3 (1922), 133-181

[4] Beg, I. and Shahzad, N., Applications of the proximity map to random fixed point theorems in Hilbert spaces, J. Math. Anal. Appl., 196 (1995), 606-613

[5] Beg, I. and Abbas, M., Random fixed point theorems for Caristi type random operators, J. Appl. Math. Comput, 25 (2007), No. 1-2, 425-437

[6] Bharucha-Reid, A. T., Fixed point theorems in probabilistic analysis, Bull. Amer. Math. Soc., 82 (1976), 641-645

[7] Caristi, J., Fixed point theorems for mappings satisfying inwardness conditions, Trans. Amer. Math. Soc., 215 (1976), 241-251

[8] Downing, D. and Kirk, M. A., A generalization of Caristi's theorem with applications to nonlinear mapping theory, Pacific J. Math., 69 (1977), No. 2 , 339-346

[9] Ekeland, I., On the variational principle, J. Math. Anal. Appl., 47 (1974), 324-353

[10] Hans, O., Reduzierende zufallige Transformationen (Czech), Czechoslovak Math. J., 7 (1957), 154-158

[11] Itoh, S., Random fixed-point theorems with an application to random differential equations in Banach spaces, J. Math. Anal. Appl., 67 (1979), No. 2, 261-273

[12] Itoh, S., A random fixed point theorem for a multivalued contraction mapping, Pacific J. Math., 68 (1977), No. 1, $85-90$

[13] Kumam, P., Fixed point theorem and random fixed point theorems for set-valued non-self mappings, Thai J. Math., 2 (2004), No. 2, 295-307

[14] Kumam, P. and Plubtieng, S., The characteristic of noncompact convexity and random fixed point theorem for set-valued operators, Czechoslovak Math. J., 57 (132) (2007), No. 1, 269-279

[15] Spacek, A., Zufallige Gleichungen, Czechoslovak Math. J., 5 (1955), 462-466

[16] Suzuki, T., On Downing-Kirk's theorem, J. Math. Anal. Appl., 286 (2003), 453-458

[17] Suzuki, T., Generalized Caristi's fixed point theorems by Bae and others, J. Math. Anal. Appl., 302 (2005), 502-508

Received: 02.06.2015; In revised form: 04.04.2016; Accepted: 15.04.2016

2010 Mathematics Subject Classification. 47H10, 47H40.

Key words and phrases. Caristi's random fixed point theorem, generalized distance, Polish space.

Corresponding author: Somyot Plubtieng; Somyotp@nu.ac.th 
[18] Suzuki, T., Generalized distance and existence theorems in complete metric spaces, J. Math. Anal. Appl., 253 (2001), 440-458

1 Department of Mathematics

FACULTY OF SCIENCE, NARESUAN UNIVERSITY

PHITSANULOK 65000, THAILAND.

E-mail address: Somyotp@nu.ac.th

2 Center of Excellence in Mathematics

FACULTY OF SCIENCE, NARESUAN UNIVERSITY

PHITSANULOK 65000, THAILAND.

E-mail address: Naomi_115@hotmail.com 